Published in: Materials Science and Engineering A, 410-411 (2005) 303-307

\title{
Microstructural evolution in a spray-cast aluminum alloy during equal-channel angular pressing
}

\author{
Nong Gao ${ }^{\mathrm{a}, ~}{ }^{*}$, Marco J. Starink ${ }^{\mathrm{a}}$, Minoru Furukawa ${ }^{\mathrm{b}}$, Zenji Horita ${ }^{\mathrm{c}}$, Cheng Xu ${ }^{\mathrm{d}}$, \\ Terence G. Langdon ${ }^{\mathrm{d}}$ \\ ${ }^{a}$ Materials Research Group, School of Engineering Sciences \\ University of Southampton, Southampton SO17 1BJ, U.K. \\ ${ }^{\mathrm{b}}$ Department of Technology, Fukuoka University of Education \\ Munakata, Fukuoka 811-8581, Japan \\ ${ }^{\mathrm{c}}$ Department of Materials Science and Engineering, Faculty of Engineering \\ Kyushu University, Fukuoka 812-4192, Japan \\ ${ }^{\mathrm{d}}$ Departments of Aerospace \& Mechanical Engineering and Materials Science \\ University of Southern California, Los Angeles, CA 90089-1453, U.S.A.
}

\begin{abstract}
A spray-cast Al-7034 alloy was processed by equal-channel angular pressing (ECAP) to a total of 8 passes at $473 \mathrm{~K}$ and the pressed samples were examined using transmission electron microscopy, differential scanning calorimetry and electron back-scatter diffraction. It is shown that the grain size of the alloy is reduced to $\sim 0.3 \mu \mathrm{m}$ by ECAP and the high pressures associated with ECAP lead to a fragmentation of the rod-like $\eta$-phase. The high temperature of ECAP also produces a precipitation of $\eta$-phase. There is an increase in the fraction of high-angle boundaries during the initial passes of ECAP but the fraction of low-angle boundaries remains high even after 8 passes.
\end{abstract}

Keywords: Equal-channel angular pressing; Grain boundary misorientation; Precipitation; Thermal processes; Ultrafine grains

\footnotetext{
${ }^{*}$ Corresponding author. Tel.: +44-238-059-3396; fax: +44-238-059-3016.

E-mail address: n.gao@soton.ac.uk (N. Gao)
} 


\section{Introduction}

Equal-channel angular pressing (ECAP) is a processing technique, developed more than twenty years ago [1], in which a bulk metal is pressed through a die constrained within a channel bent through an abrupt angle at, or very close to, $90^{\circ}$. Processing by ECAP has become of special interest over the last decade with the realization that it provides a simple means of achieving remarkable grain refinement in bulk metals [2.3]. For example, metals processed by ECAP typically have grain sizes in the submicrometer range, where these sizes are smaller than the sizes attained using conventional thermomechanical processing.

Although the major interest in recent years has focused almost exclusively on making use of ECAP to develop ultrafine grain sizes in a range of materials, very recent results have shown that the high pressures inherent in ECAP may lead also to a breaking of precipitates in metallic alloys [4-6]. In particular, a recent report described the fragmentation of the rod-like $\eta$-phase in an Al-7034 alloy during ECAP [7]. The present paper extends this work on the Al-7034 alloy by examining the evolution of the microstructure with consecutive passes through the ECAP die using differential scanning calorimetry (DSC) and electron back-scatter diffraction (EBSD) analysis.

\section{Experimental material and procedures}

The experiments were conducted using a commercial Al-7034 alloy produced by spray-casting: the earlier report contained full details of the initial processing of the alloy [7]. The material was produced in the form of an ingot with a diameter of $356 \mathrm{~mm}$. It was then extruded using an extrusion ratio of 35 to give a rod having a diameter of $63.5 \mathrm{~mm}$. This rod was homogenized for $16 \mathrm{~h}$ at $733 \mathrm{~K}$, air cooled and then extruded using an extrusion ratio of 50 in a single pass to give several rods having diameters of $9.5 \mathrm{~mm}$. Each rod was cut into a series of billets having lengths of $64 \mathrm{~mm}$. Microscopic inspection revealed a grain size of $\sim 2.1 \mu \mathrm{m}$ in the 
as-received alloy and a chemical analysis gave a composition (in wt.\%) of $11.5 \% \mathrm{Zn}, 2.5 \% \mathrm{Mg}$, $0.9 \% \mathrm{Cu}$ and $0.20 \% \mathrm{Zr}$ with the balance as $\mathrm{Al}$.

The ECAP processing was conducted at a temperature of $473 \mathrm{~K}$ using a solid die having an internal channel bent through an angle, $\Phi$, of $90^{\circ}$ and with an angle, $\Psi$, of $20^{\circ}$ representing the outer arc of curvature where the two parts of the channel intersect. It was shown earlier, in experiments on pure $\mathrm{Al}$, that no microstructural inhomogeneities are introduced in ECAP by using a die with an outer round corner of $\Psi=20^{\circ}$ [8]. It can be shown that pressing with a die having internal angles of $\Phi=90^{\circ}$ and $\Psi=20^{\circ}$ gives an imposed strain close to $\sim 1$ on passage of the sample through the die [9]. In the present experiments, the samples were pressed repetitively up to a maximum of 8 passes to give a maximum strain of $\sim 8$ using route $\mathrm{B}_{\mathrm{C}}$ in which the sample is rotated by $90^{\circ}$ in the same sense between each consecutive pass [10].

Microstructures were examined before and after ECAP using an Hitachi H-8100 transmission electron microscope operating at $200 \mathrm{kV}$. For samples subjected to ECAP, these observations were made on the flow or Y plane equivalent to the side face at the point of exit from the die. EBSD analysis was performed using a JEOL JSM-6500 high-performance scanning electron microscope with an individual step size of $0.05 \mu \mathrm{m}$. The EBSD data were analyzed using HKL Channel 5 software. Differential scanning calorimetry (DSC) was performed using a Perkin-Elmer Pyris 1 calorimeter with a nitrogen atmosphere and a constant heating rate of $10 \mathrm{~K} \mathrm{~min}^{-1}$. The samples were in the form of disks with diameters of $\sim 5.0 \mathrm{~mm}$ and thicknesses of $\sim 0.9 \mathrm{~mm}$. Corrections were applied to the DSC runs by subtracting the DSC baseline obtained from a run with an empty pan. An additional baseline correction was also applied by subtracting a second-order polynomial function from the measured heat flows to compensate for heat capacity differences and apparatus imperfections leading to short-term and 
long-term baseline drifts. The parameters were ultimately fitted by putting the heat flows equal to zero at the three temperatures of 353, 453 and $793 \mathrm{~K}$.

\section{Experimental results and discussion}

Inspection of the samples by transmission electron microscope revealed very significant differences between the microstructures in the as-received and as-pressed conditions. An example is shown in Fig. 1 where (a) shows the as-received alloy and (b) shows the microstructure at the same magnification after 6 passes of ECAP. An important characteristic of the as-received spray-cast alloy was the presence of large rod-like precipitates representing the $\eta$-phase $\left(\mathrm{MgZn}_{2}\right)$. Detailed inspection showed these precipitates were distributed reasonably homogeneously throughout the alloy and measurements gave average lengths and diameters of $\sim 0.5$ and $\sim 0.07 \mu \mathrm{m}$, respectively. There was also evidence in the as-received condition for a fine dispersion of $\mathrm{Al}_{3} \mathrm{Zr}$ precipitates and $\eta^{\prime}$-phase and it is evident from Fig. 1(a) that the initial density of intragranular dislocations was low. By contrast, Fig. 1(b) shows the rod-like precipitates are absent after processing to a strain of $\sim 6$ but there is now a dispersion of fine $\eta$ phase precipitates. In addition, measurements gave a grain size of $\sim 0.3 \mu \mathrm{m}$ after ECAP where this is significantly smaller than the as-received grain size of $\sim 2.1 \mu \mathrm{m}$. It is concluded from the TEM observations that ECAP at $473 \mathrm{~K}$ leads to a very substantial grain refinement and a fragmentation of the long rod-like $\eta$-phase precipitates.

Fig. 2(a) shows the DSC thermograms recorded over the entire range of heating temperatures and Fig. 2(b) shows a magnified view for temperatures above $640 \mathrm{~K}$. These various curves are generally similar to those reported for other 7xxx-series alloys when treated to peak-aged and over-aged tempers $[11,12]$. For ease in interpretation, the primary thermal effects 
are labeled from I to VI in Fig. 2(a), where the various regions represent dissolution of GuinierPreston (GP) zones and/or the $\eta^{\prime}$-phase (I), formation of the $\eta$-phase (II), coarsening of rounded disks of the $\eta$-phase precipitates (III), dissolution of the $\eta$-phase (IV), incipient melting of the Tphase representing a quaternary phase based on $\mathrm{Mg}_{3} \mathrm{Zn}_{3} \mathrm{Al}_{2}(\mathrm{~V})$ and the onset of full melting of the alloy (VI).

Inspection of Fig. 2(a) reveals significant differences between the curves obtained for the as-received alloy and for the samples after 1, 4 and 8 passes of ECAP. For as-received material, the dissolution of Guinier-Preston (GP) zones and/or the $\eta^{\prime}$-phase (I) occurs on heating to the ECAP processing temperature of $473 \mathrm{~K}$ and precipitation of the $\eta$-phase starts when the material approaches the ECAP processing temperature. This reaction is expected to continue during the ECAP processing, and it is apparent that this reaction is completed in the early stages of ECAP because heat effects I and II are absent for the alloy processed through only a single pass of ECAP. Coarsening of the $\eta$-phase occurs on continued exposure at the processing temperature and thus on subsequent passes through the ECAP die. In general, these results are consistent with earlier reports of the precipitation reactions occurring in similar alloys [13-16] but in the present experiments the precipitation of the $\eta$-phase can be especially favored because of the introduction by ECAP of a very high density of intragranular dislocations which provides a source of potential nucleation sites. It is important to note also that the precipitation and coarsening of the $\eta$-phase leads to rounded (disc-shaped) precipitates which are different from the larger angular precipitates resulting from fragmentation of the long rod-like $\eta$-phase precipitates present in the as-received alloy.

An additional feature of the DSC curves is visible in Fig. 2(b) where the trough associated with dissolution of the $\eta$-phase occurs in the vicinity of $700 \mathrm{~K}$ in the as-received billet 
and after 1 and 4 passes whereas it is displaced to $670 \mathrm{~K}$ after 8 passes. This displacement is associated with the size and distributions of the fragmented $\eta$-phase particles since, making the reasonable assumption that 8 passes represents the most fragmented condition, the dissolution will become easier for the billet subjected to 8 passes. There is also a clear melting of the Tphase at $750 \mathrm{~K}$ after 8 passes of ECAP and to a lesser extent after 4 passes. This may be associated with the occurrence of T-phase precipitation which is known to occur at the ECAP temperature of $473 \mathrm{~K}$ [17].

Fig. 3 shows typical grain boundary maps for (a) the as-received condition and after (b) 1, (c) 4 and (d) 8 passes of ECAP: the solid lines denote the boundaries having high angles of misorientation $\left(\geq 15^{\circ}\right)$ and the faint lines show the low-angle boundaries. Inspection of Figs. 3(c) and (d) provides a clear demonstration of the very marked refinement that may be attained through processing by ECAP through a reasonable number of passes. The misorientation distributions associated with these four maps is shown in Fig. 4 where the histograms represent the frequency of occurrence of boundaries falling within each angular increment of $3^{\circ}$ and the solid lines denote the conventional Mackenzie theoretical plot for the distribution of misorientations in a randomly-oriented polycrystal [18]. It is apparent that the as-received microstructure contains both a high fraction of low-angle boundaries and an exceptionally large peak at an angle in the vicinity of $\sim 55^{\circ}$. This peak is due to the presence of a very strong texture in the as-received material and a high fraction of $\Sigma 3$ coincidence site lattice (CSL) boundaries [19,20]. It is apparent from Fig. 4(b) there is a very high fraction of low-angle boundaries after 1 pass but this fraction decreases, but is not removed, with subsequent passes. After 4 and 8 passes, shown in Figs 4(c) and (d), there are essentially bimodal distributions with peaks at both $\sim 50^{\circ}$ and at the lowest angles. The failure to attain a true Mackenzie distribution in ECAP processing is due to the continuous introduction of new dislocations, and the relaxation of these 
dislocations into low-angle boundaries, on each separate passage through the die. These trends are generally consistent with those reported for pure aluminum, other Al-based alloys and pure Ni after processing by ECAP [21-25].

\section{Summary and conclusions}

1. A spray-cast Al-7034 alloy, having an initial grain size of $\sim 2.1 \mu \mathrm{m}$, was processed by ECAP at $473 \mathrm{~K}$ up to a total of 8 passes, equivalent to an imposed strain of $\sim 8$. The alloy was examined after processing using TEM, DSC and EBSD.

2. The results show ECAP reduces the grain size to $\sim 0.3 \mu \mathrm{m}$ and the high pressure associated with the pressing leads to a fragmentation of the rod-like $\eta$-phase. There is also a

dissolution of the $\eta^{\prime}$-phase on heating to the pressing remperature $473 \mathrm{~K}$. Formation and subsequent coarsening of the disc shaped $\eta$-phase precipitates occurs at the pressing temperature.

3. There is an increase in the fraction of high-angle grain boundaries with increasing numbers of ECAP passes but, due to the continuous introduction of dislocations in each separate pass, there is a significant fraction of low-angle boundaries even after 8 passes.

\section{Acknowledgements}

This work was supported in part by a Grant-in-Aid for Scientific Research from the Ministry of Education, Science, Sports and Culture of Japan, in part by the Light Metals Educational Foundation of Japan and in part by the National Science Foundation of the United States under Grant No. DMR-0243331. 


\section{References}

1. V.M. Segal, V.I. Reznikov, A.E. Drobyshevskiy, V.I. Kopylov, Russian Metallurgy 1 (1981) 99.

2. $\quad$ R.Z. Valiev, N.A. Krasilnikov, N.K. Tsenev, Mater. Sci. Eng. A137 (1991) 35.

3. R.Z. Valiev, A.V. Korznikov, R.R. Mulyukov, Mater. Sci. Eng. A168 (1993) 141.

4. M. Murayama, Z. Horita, K. Hono, Acta Mater. 49 (2001) 21.

5. K. Oh-ishi, Y. Hashi, A. Sadakata, K. Kaneko, Z. Horita, T.G. Langdon, Mater. Sci. Forum 396-402 (2002) 333.

6. C.Y. Nam, J.H. Han, Y.H. Chung, M.C. Shin, Mater. Sci. Eng. A347 (2003) 255.

7. C. Xu, M. Furukawa, Z. Horita, T.G. Langdon, Acta Mater. 51 (2003) 6139.

8. C. Xu, T.G. Langdon, Scripta Mater. 48 (2003) 1.

9. Y. Iwahashi, J. Wang, Z. Horita, M. Nemoto, T.G. Langdon, Scripta Mater. 35 (1996) 143.

10. M. Furukawa, Y. Iwahashi, Z. Horita, M. Nemoto, T.G. Langdon, Mater. Sci. Eng. A257 (1998) 328.

11. M.J. Starink, X.M. Li, Metall. Mater. Trans. 34A (2003) 899.

12. M.J. Starink, S.C. Wang, Acta Mater. 51 (2003) 5131.

13. R.M. Allen, J.B. Vande Sande, Metall. Mater. Trans. 9A (1978) 1251.

14. R.M. Allen, J.B. Vande Sande, Acta Metall. 28 (1980) 1185.

15. K. Stiller, P.J. Warren, V. Hansen, J. Angenete, J. Gjønnes, Mater. Sci. Eng. A270 (1999) 55.

16. V. Hansen, O.B. Karlsen, Y. Langsrud, J. Gjønnes, Mater. Sci. Tech. 20 (2004) 185.

17. A. Deschamps, F. Livet, Y. Bréchet, Acta Mater. 47 (1999) 281.

18. J.K. Mackenzie, Biometrika 45 (1958) 229.

19. T. Watanabe, Textures and Microstructures 20 (1993) 195. 
20. K. Harada, S. Tsurekawa, T. Watanabe, G. Palumbo, Scripta Mater. 49 (2003) 367.

21. J.-Y. Chang, J.-S. Yoon, G.-H. Kim, Scripta Mater. 45 (2001) 347.

22. S.D. Terhune, D.L. Swisher, K. Oh-ishi, Z. Horita, T.G. Langdon, T.R. McNelley, Metall. Mater. Trans. 33A (2002) 2173.

23. A.P. Zhilyaev, B.-K. Kim, G.V. Nurislamova, M.D. Baró, J.A. Szpunar, T.G. Langdon, Scripta Mater. 46 (2002) 575.

24. P.L. Sun, C.Y. Yu, P.W. Kao, C.P. Chang, Scripta Mater. 47 (2002) 377.

25. P.-L. Sun, P.-W. Kao, C.-P. Chang, Metall. Mater. Trans. 35A (2004) 1359. 


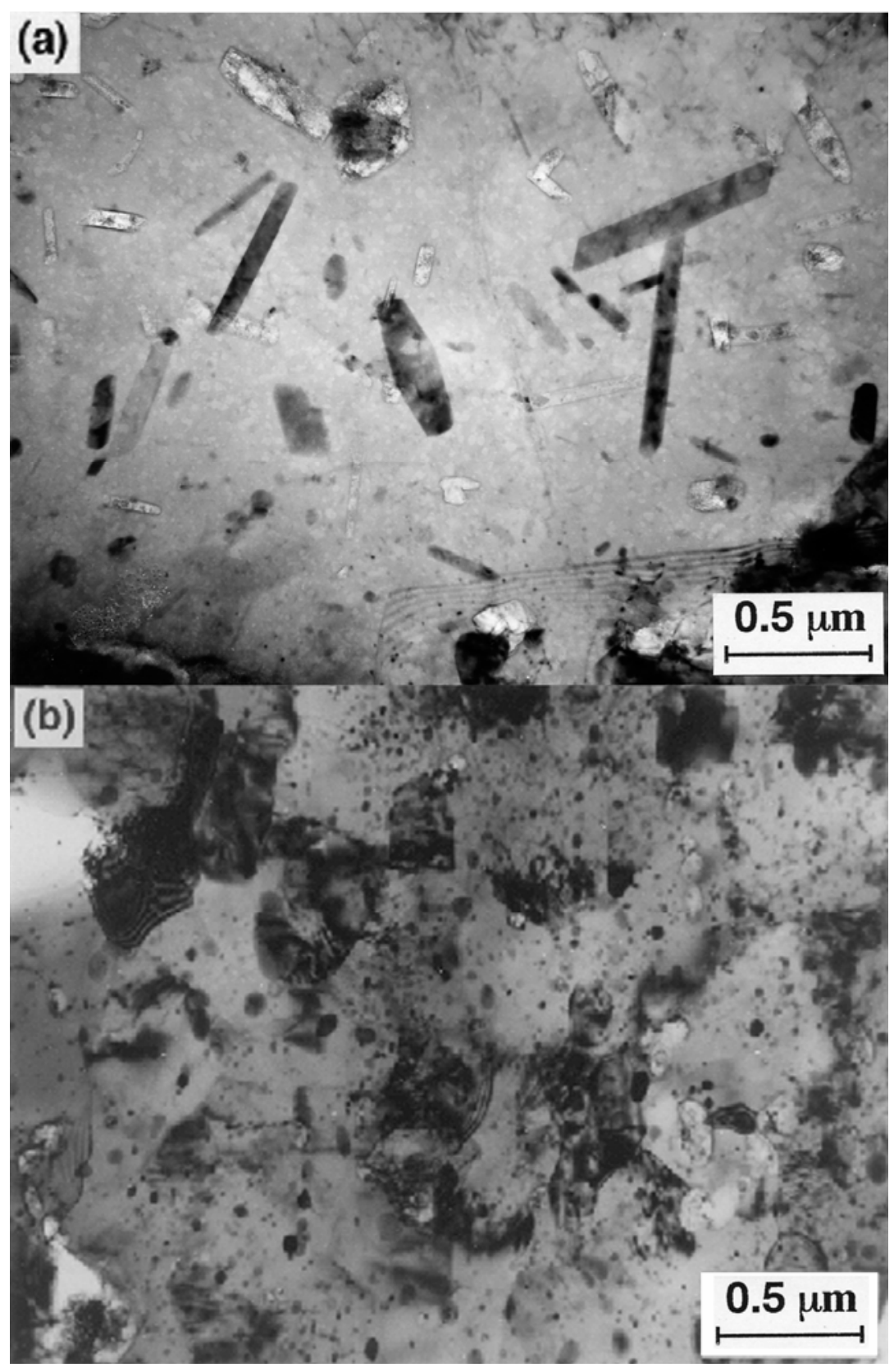

Fig. 1. Microstructures in the as-received Al-7034 alloy in (a) the as-received condition and (b) after ECAP through 6 passes at $473 \mathrm{~K}$. 

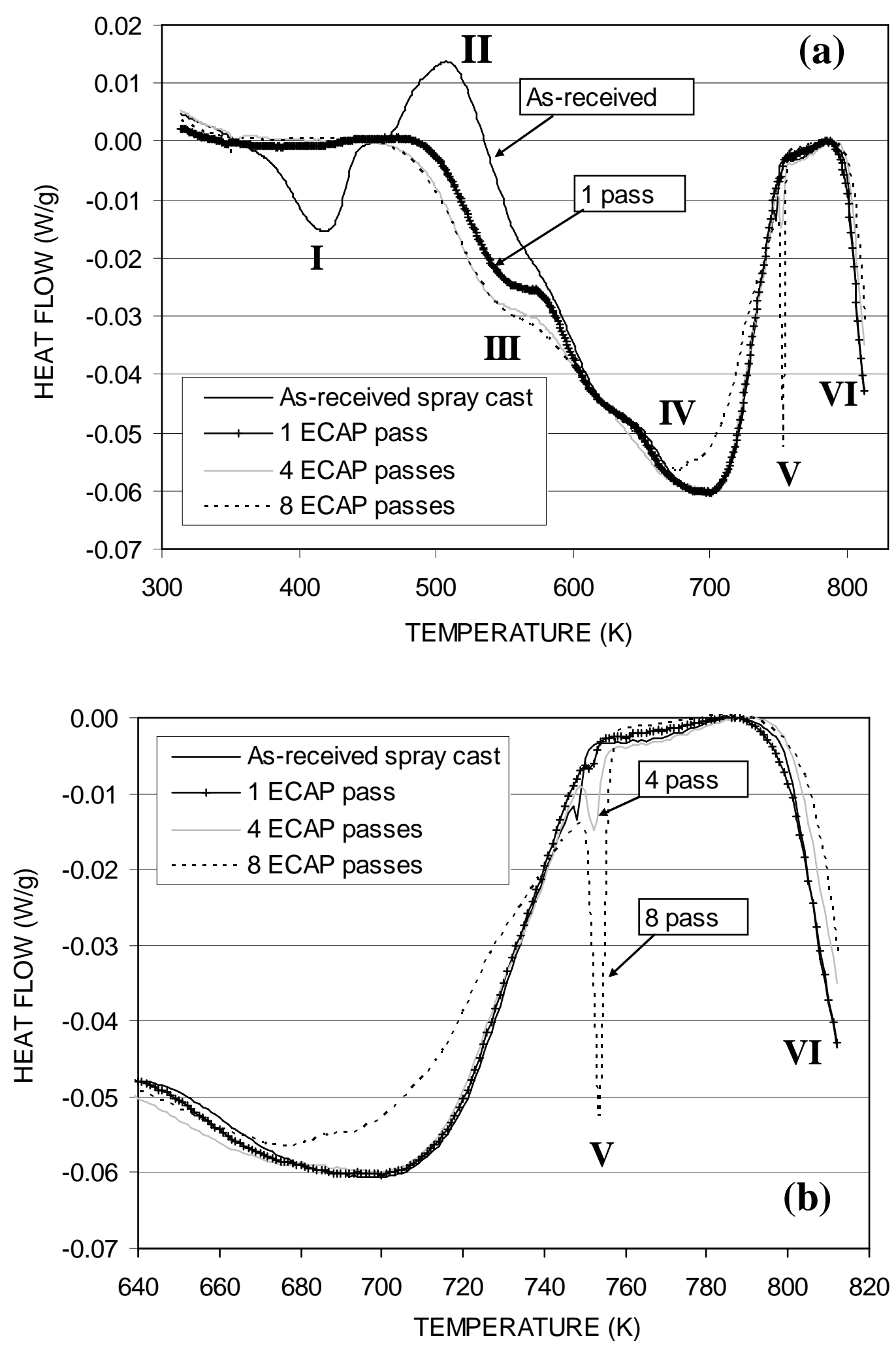

Fig. 2. The DSC thermograms obtained over a range of temperatures for the as-received material and after 1, 4 and 8 passes of ECAP: (a) overview covering all heating temperatures and (b) magnified detail above a temperature of $\sim 640 \mathrm{~K}$. 

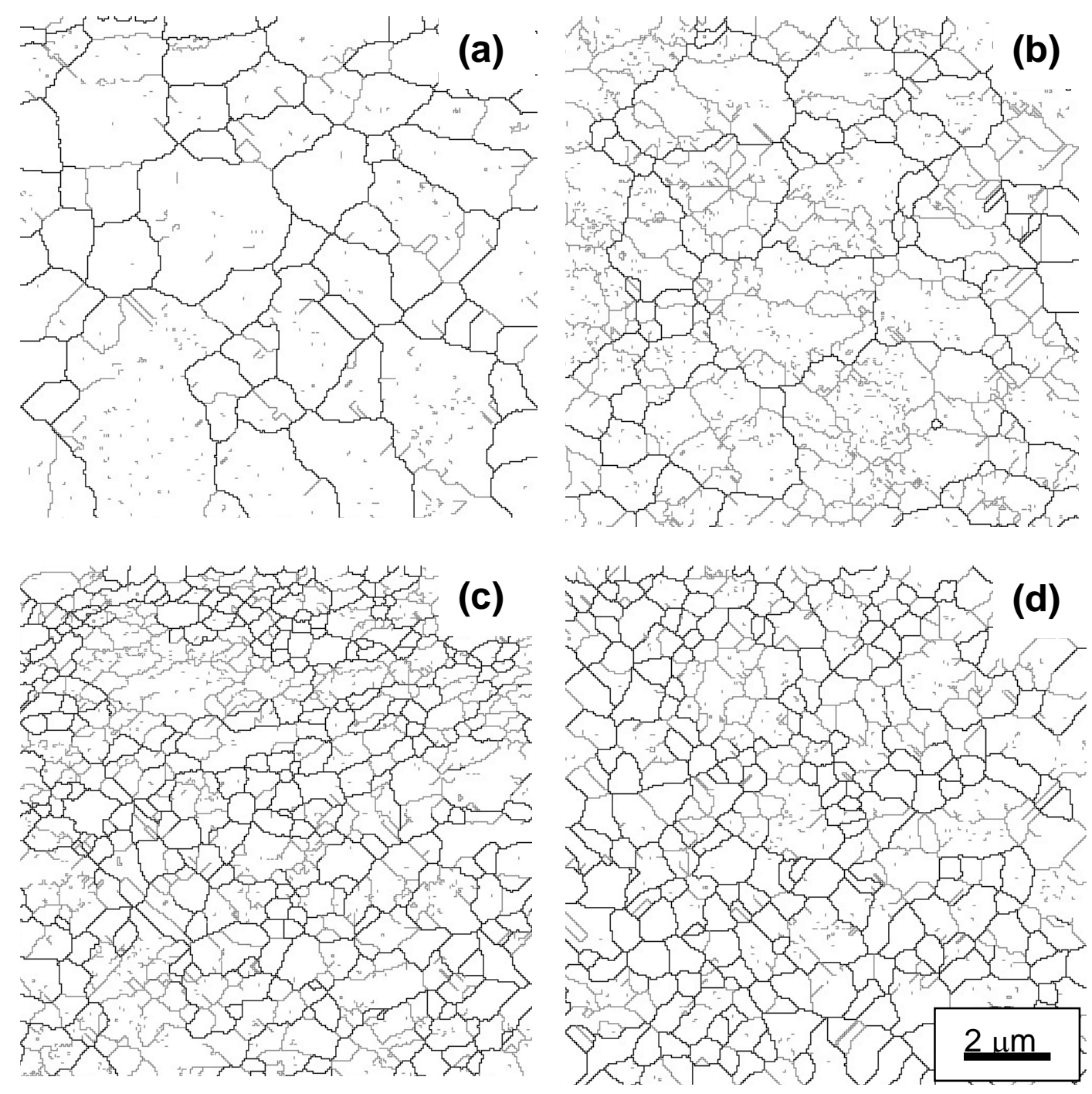

Fig. 3. Grain distributions in the Al-7034 alloy in (a) the as-received condition and after (b) 1, (c) 4 and (d) 8 passes of ECAP. 

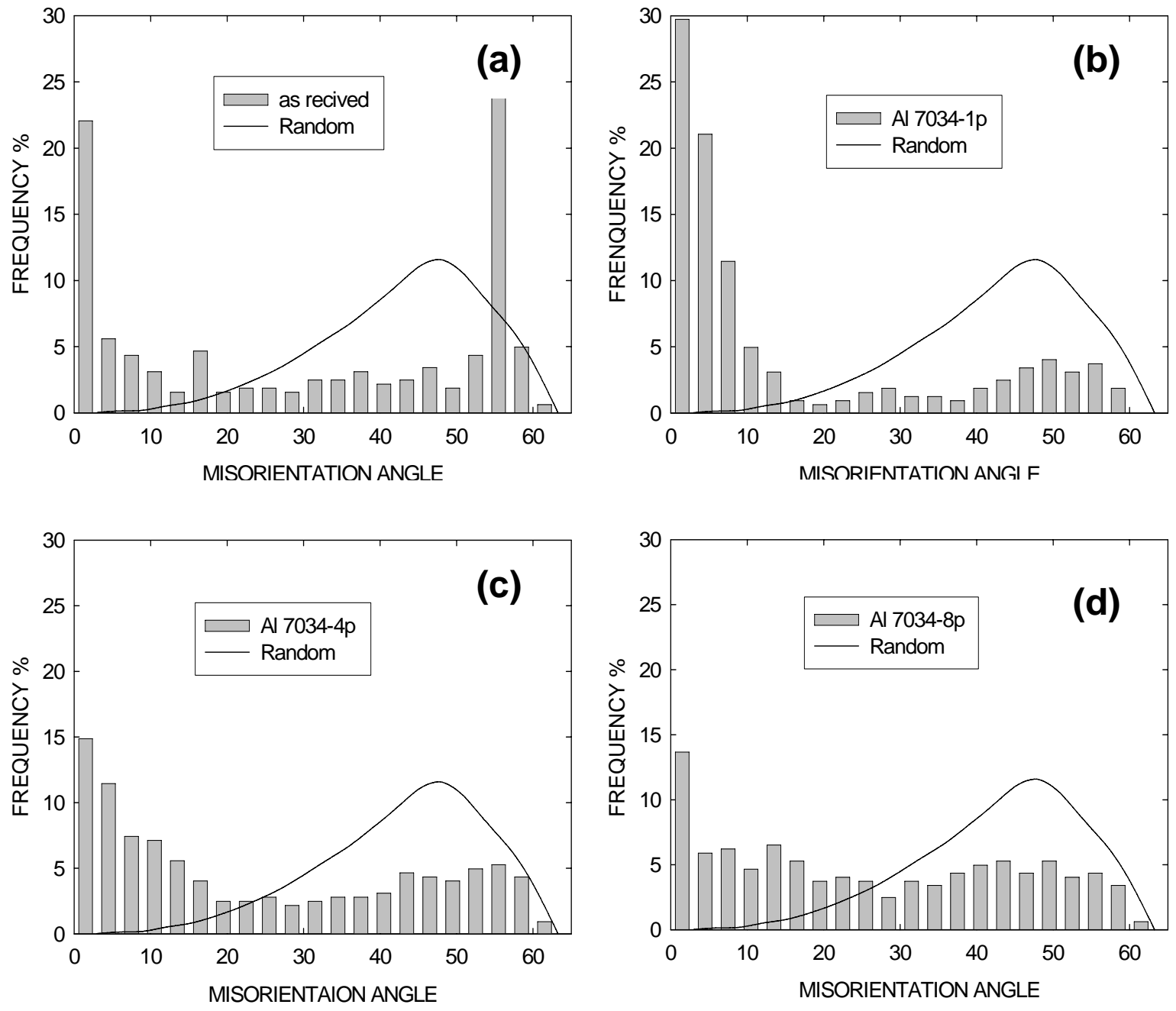

Fig. 4. Grain boundary misorientation distributions in the Al-7034 alloy in (a) the as-received condition and after (b) 1, (c) 4 and (d) 8 passes of ECAP. 